http://jmscr.igmpublication.org/home/ ISSN (e)-2347-176x ISSN (p) 2455-0450 crossref DOI: https://dx.doi.org/10.18535/jmscr/v8i1.77

\title{
Paracentesis A Diagnostic Adjuvant in Abdominal Emergency
}

\author{
Authors \\ Prof. (Dr) Braja Mohan Mishra ${ }^{1}$, Dr Rabi Narayan Guru ${ }^{2 *}$, Dr Biswajeet Pusty ${ }^{3}$ \\ ${ }^{1}$ Professor \& H.O.D Department of General Surgery, VIMSAR, Burla, Odisha, India \\ ${ }^{2}$ Asst. Professor, Department of General Surgery, VIMSAR, Burla, Odisha, India \\ ${ }^{3}$ Junior Resident, Department of General Surgery, VIMSAR, Burla, Odisha, India \\ *Corresponding Author \\ Dr Rabi Narayan Guru
}

\begin{abstract}
Introduction: Peritoneal paracentesisis safe procedure in case of abdomen emergency in both traumatic and non traumatic cases.

Materials \& Methods: All patients who present with acute abdomen including traumatic cases and non traumatic cases except obstruction cases were included.A total no 100 cases (80non-traumatic case and 20traumatic cases) were studied during this period

Results: In present study of 100cases we could aspirate the characteristic fluid in 78 cases. The most common type of fluid was billous in 40cases. Haemorrhagic in 20 cases and restarepurulent and feculent. All aspirated fluid sent for culture and sensitive test

Conclusion: Peritoneal Paracentesis is a diagnostic aid in acute abdomen in limited resource area.

Keywords: peritoneal Paracentesis, acute abdomen billous fluid.
\end{abstract}

\section{Introduction}

Abdominal Tapping is percutaneous removal of peritoneal fluid which provides a rapid, easy and safe method of diagnosing intraperitoneal diseases and abdominal effusion.

Abdominal emergency poses a great difficulty to the surgeon in arriving at an early and accurate diagnosis due to the following factors. Laparotomy for non-surgical conditions i.e. false acute abdominal emergency cases give rise to deleterious effect rather than benefit. Innonsurgical conditions of abdomen like acute myocardial infarction, infective hepatitis, acute rheumatic fever, congestive cardiac failure and diabetic acidosis abdominal surgery is absolutely contra-indicated, even though patients present with severe, agonizing abdominal pain. On the other hand the delay in definitive diagnosis and prompt surgical intervention leads to high mortality and morbidity in the "Real Abdominal Emergency". Real Abdominal emergency may be traumatic and non-traumatic.

Very often, surgeons are confronted with cases where the so called text book description may not be present in all cases or even if present are often confusing. Some important features as tenderness, rigidity may be absent or their interpretation may prove very difficult particularly in unconscious patients with multiple injuries or associated head injury, intoxication or post-concussion. Confusion, somnolence or due to associated medical conditions. Patients on steroid therapy 
and those seriously ill manifest only mild features, and in infants and children the signs and symptoms are very difficult to interpret.

Now-a-days, many sophisticated investigative procedures like Ultra sound, C.T. Scan and Arteriogram are available to reach at the diagnosis. Such facilities are not available to thousands of treating centres of India. Even the simple radiogram which contributes to $75 \%$ in diagnosis of acute abdominal conditions, which is not available at district levels.

Simple radiography shows evidence of perforation in gastro-intestinal tract in only $75 \%$ of cases of perforations by showing free gas under the diaphragm. In these cases also it does not give any clue as to be sites of perforation (i.e. gastric duodenal, ileal or colonic) but peritoneal tapping can be of help in diagnosing the radiographically negative cases. Moreover the site of perforation may be known in cases with some amount of certainty. Thus aspiration of abdominal cavity can help the surgeon to make proper diagnosis and thereby influence the decision of operative approach.

Secondly peritoneal tapping has a definite role in the management of blunt and penetrating injury of abdomen. Frank blood on peritoneal tap or blood stained fluid after lavage with a litre of normal saline, suggests rupture of intra-abdominal viscera which requires immediate operative intervention. Therefore, the present study is designed and carried out to know the role of tapping in acute abdominal conditions for diagnostic purposes and to advocate its use as a harmless and very safe method that would modify the mode of management in abdominal emergency.

\section{Materials and Methods}

The study has been undertaken on a group of patients irrespective of age and sex from V.S.S. Medical college Hospital, Burla during the period of November 2017to October 2019.

100 patients selected randomly out of all patients of acute abdomen from different surgical units either directly from outdoors and casualty section or referred from other Departments with features of abdominal emergency.

A detailed clinical history was taken and physical examination was done. Gastric aspirate, urine and blood was collected for routine and microscopic investigations. Every patient was subjected to radiological studies.

Diagnostic peritoneal tapping was carried out as detailed and the results interpreted..

\section{Observation}

Table - 1 Age and Sex Incidence of the Study

\begin{tabular}{|c|c|c|c|c|c|c|c|c|}
\hline \multirow{2}{*}{$\begin{array}{l}\text { Age Group in } \\
\text { years }\end{array}$} & \multicolumn{3}{|c|}{ Acute Nontraumatic } & \multicolumn{3}{|c|}{ Traumatic } & \multirow{2}{*}{$\begin{array}{l}\text { No. of } \\
\text { cases }\end{array}$} & \multirow{2}{*}{$\%$} \\
\hline & Male & Female & Total & Male & Female & Total & & \\
\hline $13-20$ & 5 & 2 & 7 & 2 & 1 & 2 & 10 & 10 \\
\hline $21-30$ & 5 & 5 & 10 & 4 & 1 & 5 & 15 & 15 \\
\hline $31-40$ & 21 & 5 & 26 & 5 & 1 & 6 & 32 & 32 \\
\hline $41-50$ & 17 & 4 & 21 & 2 & 0 & 2 & 23 & 23 \\
\hline $51-60$ & 8 & 2 & 10 & 2 & 1 & 3 & 13 & 13 \\
\hline $61-70$ & 2 & 2 & 4 & 1 & 0 & 1 & 5 & 5 \\
\hline $71-80$ & 2 & 0 & 2 & 0 & 0 & 0 & 2 & 2 \\
\hline Total & 60 & 20 & 80 & 16 & 4 & 20 & 100 & 100 \\
\hline
\end{tabular}

A group of 80 acute non traumatic cases and 20 traumatic cases out of total 100 cases in acute abdominal emergency were included in the study of "Abnorminal Paracentesis" - A diagnostic adjuvant in abdominal emergency.
Table 1 : Shows the sex ratio as follows :

Acute non - Traumatic cases : 80 cases

Male : Female : $60: 20$

Acute Traumatic cases : 20 cases

Male : Female : $16: 4$

Total Cases - Male : Female : 76:24 
Table - 2 (A) Group of Cases and Result of Tap in Non Traumatic Case

\begin{tabular}{|l|c|c|}
\hline Group of cases & No. of cases & +ve tap \\
\hline Perforated peptic ulcer (Gastric \& duodenal) & 51 & 41 \\
\hline Ileal perforation & 11 & 9 \\
\hline Perforated appendix & 16 & 8 \\
\hline Ectopic pregnancy & 2 & 2 \\
\hline Total & 80 & 65 \\
\hline
\end{tabular}

The above table - 2 (A) Shows Gastro-intestinal perforation cases are more sensitive to tapping because mostly in the lower quadrant it was positive in $1^{\text {st }}$ attempt and there was no false negative tap. Among this group peptic perforation is more common in 41 cases out of 51 cases. In acute inflammatory cases in which acute appendicitis was more common which shows 8 positive cases and 8 negative cases.

Table - 2 (B) Group of Cases and with the Result of Tap in Traumatic Case

\begin{tabular}{|c|c|c|c|c|c|c|}
\hline \multirow{2}{*}{\multicolumn{2}{|c|}{ Group of cases }} & \multirow{3}{*}{$\begin{array}{l}\text { No. of } \\
\text { cases }\end{array}$} & \multicolumn{2}{|c|}{ Positive } & \multicolumn{2}{|c|}{ Negative } \\
\hline & & & \multirow[t]{2}{*}{ True } & \multirow[t]{2}{*}{ False } & \multirow{2}{*}{ True } & \multirow{2}{*}{ False } \\
\hline A. & TRAUMATIC & & & & & \\
\hline \multirow[t]{4}{*}{ a. } & Blunt Trauma & (10) & & & & \\
\hline & 1. Solid visceral and /or mesentery & 7 & 6 & - & - & 1 \\
\hline & 2. Hollow viscera and/or mesentery & 2 & 2 & - & - & - \\
\hline & 3. Injury to only mesentery \& others & 1 & 1 & - & - & - \\
\hline \multirow[t]{4}{*}{ b. } & Penetrating Trauma & (8) & & & & \\
\hline & 1. Solid visceral and /or mesentery & 3 & 2 & - & - & 1 \\
\hline & 2. Hollow viscera and/or mesentery & 3 & 3 & - & - & - \\
\hline & 3. Injury to only mesentery \& others & 2 & 2 & - & - & - \\
\hline \multirow[t]{4}{*}{ c. } & Lacerated Injury & (2) & & & & \\
\hline & 1. Solid visceral and /or mesentery & 1 & 1 & - & - & - \\
\hline & 2. Hollow viscera and/or mesentery & 1 & 1 & - & - & - \\
\hline & Injury to only mesentery \& others & 0 & 0 & - & - & - \\
\hline \multicolumn{2}{|c|}{ Total } & 20 & 18 & - & - & 2 \\
\hline
\end{tabular}

Table 2 (B) shows in traumatic group 18 out of 20 acute abdominal emergency the false negative cases, are positive. Thus in this study over all result is only $10 \%$.

Table 3 Relative Incidences of Clinical Features

\begin{tabular}{|c|c|c|c|}
\hline Clinical Features & No. of patients & Out patients & Percentage \\
\hline 1. $\quad$ Pain & 77 & 80 & 96 \\
\hline 2. Vomiting & 64 & 80 & 80 \\
\hline 3. $\quad$ Tenderness & 64 & 80 & 80 \\
\hline 4. $\quad$ Rigidity & 74 & 100 & 74 \\
\hline 5. Distension of abdomen & 46 & 100 & 46 \\
\hline 6. $\quad$ Obliteration of liver dullness & 43 & 100 & 43 \\
\hline 7. Fever & 32 & 80 & 40 \\
\hline 8. $\quad$ Free fluid in abdomen & 36 & 100 & 36 \\
\hline $\begin{array}{lc}9 . & \text { Per rectal examination } \\
- & \text { Tenderness- 28 } \\
- & \text { Balloning-24 } \\
\end{array}$ & 26 & 80 & 32.5 \\
\hline 10. Constipation & 24 & 80 & 30 \\
\hline 11. Absence of bowel sound & 28 & 100 & 28 \\
\hline 12. Lump & 20 & 80 & 25 \\
\hline 13. Past history of peptic ulcer & 18 & 80 & 22.5 \\
\hline 14. Visible peristalsis & 15 & 80 & 18.7 \\
\hline 15. Fluid thrill & 10 & 80 & 12.5 \\
\hline 16. Shock & 12 & 100 & 12 \\
\hline 17. Unconsciousness & 3 & 100 & 3 \\
\hline
\end{tabular}

The table 3 shows pain and vomiting are the predominant presenting symptoms where rigidity and tenderness are the pre-dominant signs. 
Table - 4 Comparison of Accuracy of Tapping and Plain Radiography

\begin{tabular}{|l|l|c|c|c|}
\hline $\begin{array}{l}\text { Sl. } \\
\text { No. }\end{array}$ & Events & $\begin{array}{c}\text { No. of } \\
\text { cases }\end{array}$ & $\begin{array}{c}\text { Positive } \\
\text { Tapping }\end{array}$ & $\begin{array}{c}\text { Percentage of } \\
\text { accuracy }\end{array}$ \\
\hline 1 & Percentage of accuracy of tapping for diagnosis & & & \\
& A. Non-traumatic cases & 80 & 60 & $75 \%$ \\
& B. Traumatic cases & 20 & 18 & $90 \%$ \\
\hline & Total & $\mathbf{1 0 0}$ & $\mathbf{7 8}$ & $\mathbf{7 8 \%}$ \\
\hline 1 & Percentage of accuracy of plain Radiography of & & & \\
& abdomen & 72 & 50 & $69.44 \%$ \\
& A. Non-traumatic cases & 20 & 08 & $40 \%$ \\
& B. Traumatic cases & $\mathbf{9 2}$ & $\mathbf{5 8}$ & $\mathbf{6 3 . 0 4 \%}$ \\
\hline
\end{tabular}

Straight X-ray of abdomen, taken without preparation, in erect and supine positive and plates, obtained were looked for:

In observation it has been observed that the result of tapping is more accurate than the result of radiological study in establishing the diagnosis. Further positive result of tapping was $90 \%$ in cases of traumatic abdomen. Radiographical study showed poor result in establishing traumatic abdomen except in hollow visceral injury while in non-traumatic condition the result was encouraging.

Table - 5 Gross Appearance of Aspirate Fluid

\begin{tabular}{|l|c|c|}
\hline Sl. No. & & No. of cases \\
\hline 1. & Bilious & 40 \\
\hline 2. & Haemorrhagic & 20 \\
\hline 3. & Purulent & 15 \\
\hline 4. & Feculent & 3 \\
\hline \multicolumn{2}{|c|}{ Total } & $\mathbf{7 8}$ \\
\hline
\end{tabular}

In all the positive cases of tapping, by macroscopic study of aspirate the diagnosis was ensured by its gross appearance prospectively and it was confirmed tentatively by laparotomy in all cases.

By knowoing the type of aspirate the probable pathology could be located as in the non-traumatic group, the bilious aspirate was present in one case and on laparotomy it was seen that there was duodenal injury. It was faeculent in one case and was proved to be due to colonic injury.

Similarly in non-traumatic group the gangrenous pathology revealed haemorrhagic aspirate and the perforative old pathological group yielded purulent aspirate.

Table - 6 Site of Positive Tap And Pathology Correlated

\begin{tabular}{|c|c|c|c|c|c|c|}
\hline \multirow{2}{*}{\multicolumn{2}{|c|}{$\begin{array}{l}\text { Pathology of Intra-abdominal } \\
\text { Structure }\end{array}$}} & \multirow[b]{2}{*}{ Nos. } & \multicolumn{4}{|c|}{ Site of Puncture } \\
\hline & & & \multirow{2}{*}{$\begin{array}{c}\text { Upper } \\
\text { Right } \\
\text { Quadrant } \\
\end{array}$} & \multirow{2}{*}{$\begin{array}{c}\text { Lower } \\
\text { Right } \\
\text { Quadrant } \\
\end{array}$} & \multirow{2}{*}{$\begin{array}{l}\text { Upper left } \\
\text { Quadrant }\end{array}$} & \multirow{2}{*}{$\begin{array}{l}\text { Lower left } \\
\text { Quadrant }\end{array}$} \\
\hline 1. & \multicolumn{2}{|c|}{ 1. Injury to Solid Viscera (11) } & & & & \\
\hline & - $\quad$ Spleen (5) & 4 & -ve & -ve & +ve & $+\mathrm{ve}$ \\
\hline & & 1 & -ve & -ve & -ve & -ve \\
\hline & - $\quad$ Liver (4) & 4 & $+\mathrm{ve}$ & +ve & -ve & -ve \\
\hline & - $\quad$ Kidney (2) & 1 & $+\mathrm{ve}$ & $+\mathrm{ve}$ & -ve & -ve \\
\hline & & 1 & -ve & -ve & $+\mathrm{ve}$ & $+\mathrm{ve}$ \\
\hline \multirow[t]{5}{*}{2.} & \multicolumn{6}{|c|}{ Injury to Hollow viscera (7) } \\
\hline & - $\quad$ Duodenum (2) & 2 & $+\mathrm{ve}$ & $+\mathrm{ve}$ & -ve & -ve \\
\hline & - $\quad$ Jejunum (2) & 2 & + ve & +ve & +ve & -ve \\
\hline & - $\quad$ Ileum (2) & 2 & -ve & + ve & -ve & $+v e$ \\
\hline & $-\quad$ Colon $(1)$ & 1 & -ve & -ve & +ve & $+\mathrm{ve}$ \\
\hline \multirow[t]{2}{*}{3.} & $\begin{array}{l}\text { Injury to Mesentary\& } \\
\text { Others (2) }\end{array}$ & 1 & -ve & -ve & $+\mathrm{ve}$ & $+\mathrm{ve}$ \\
\hline & & 1 & -ve & $+\mathrm{ve}$ & $+\mathrm{ve}$ & $+\mathrm{ve}$ \\
\hline
\end{tabular}

Table No. 6 shows in traumatic injury positive taping found in upper quadrant in case of liver, 
kidney, duodenal, jejunal injury, while in case of and lower quadrant of abdomen. splenic injury positive tap present in left, upper

Table 7 Result of Peritoneal Aspiration

\begin{tabular}{|l|c|c|c|c|}
\hline \multirow{2}{*}{ Cases } & \multicolumn{3}{|c|}{ RESULTS OF TAPPING } \\
\cline { 2 - 5 } & \multicolumn{2}{|c|}{ Positive } & \multicolumn{2}{c|}{ Negative } \\
\cline { 2 - 5 } & True & False & True & False \\
\hline Non Traumatic (80) & $60(75 \%)$ & - & - & $20(25 \%)$ \\
\hline Traumatic (20) & $18(90 \%)$ & - & - & $2(10 \%)$ \\
\hline Total (100) & $\mathbf{7 8 ( 7 8 \% )}$ & - & - & $\mathbf{2 2}(\mathbf{2 2 \%})$ \\
\hline
\end{tabular}

Out of 100 cases subjected to abdominal tap 78\% were positive and $22 \%$ negative. Positive tap composed of $75 \%$ from the nontraumatic group and $90 \%$ from the traumatic group.

Table - 8 Culture \& Sensitive Result of Peritoneal Aspiration

\begin{tabular}{|l|l|c|c|}
\hline \multicolumn{2}{|l|}{ Bacteria } & No. of Cases & Percentage \\
\hline $\mathbf{1 .}$ & E. Coli alone & 36 & $60 \%$ \\
\hline $\mathbf{2 .}$ & E. Coli with other organism & 6 & $10 \%$ \\
(a) & Staphylococci (3) & & \\
(b) & Streptococci (3) & 12 & $20 \%$ \\
\hline $\mathbf{3 .}$ & Other organism alone & & \\
(a) & Klebsiella (5) & & \\
(b) & Pseudomonas (3) & & \\
(c) & Streptococcus (2) & & \\
(d) & Staphylococcus (1) & & \\
(e) & Pneumococcus (1) & 6 & \\
\hline $\mathbf{4 .}$ & Other organisms in combination & & \\
(a) & Staphylococcus with Klebsiella(4) & & \\
(b) & Streptococcus with pseudomonas (2) & $\mathbf{6 0}$ & $\mathbf{1 0 0 \%}$ \\
\hline Total & & & \\
\hline
\end{tabular}

It was observed that the E.Coli alone was the most common invader in 36 cases $(60 \%)$ in the present study, E.Coli associated with streptococcus or staphylococcus in $10 \%$ of cases.

The aspirates so collected by tapping method were sent for culture and sensitivity test for prognostic point of view. Because of early use of antibiotics in cases like colonic perforation, perforative appendicitis, gangrenous volvulus, proved effective for the early recovery of the patient. A broad spectrum antibiotic was instituted before the aspirate was sent for culture and sensitivity test. In this series the aspirate of 66 cases sent but 60 cases showed positive culture.

\section{Discussion}

In this study the peritoneal aspiration was carried out in 100 no. of patients irrespective of age group and there was no complication of aspiration itself. In both acute abdominal non-traumatic and traumatic conditions have been included. Those patients who were admitted as acute abdomen, initially with negative aspiration, but improved with conservative had been excluded from the present study.

The peritoneal tap was positive in 60 cases (75\%) out of 80 cases of acute non-traumatic abdomen and in 18 cases $(90 \%)$ out of 20 cases of acute traumatic abdomen.

An aspirate of less than $0.5 \mathrm{ml}$ need not be taken as a negative tap. Even a small quantity may be of diagnostic value if aspirated syringe is rinsed with normal saline and subjected to microscopic study for RBC and polymorph.

Limitations of the procedures were few. These are

i. The disease process must be generalized in peritoneal cavity.

ii. A minimum of $200 \mathrm{cc}$ of fluid should be present in the peritoneal cavity to give a positive tap 
iii. Sufficient quantity of fluid should be obtained for investigations.

From the gross appearance of the aspirate, the idea of underlying pathology could be determined in most of the cases. With addition of radiological and clinical features a pre-operative diagnosis could be made. 18 cases of Haemorrhagic fluid was obtained in conditions of internal injuries like ruptured liver, spleen or laceration of mesenteric vessels.

Bilious (Green) aspirate was characteristic in peptic perforation was found in 51 cases; 2 suspected cases of peptic perforation were confirmed by Bouchet's and Gmelin's Test. Ileal perforation showed feculent fluid.

Out of 66 patients sent for culture and sensitivity test of peritoneal aspirate it had been seen that 60 cases were culture positive. It was also seen that E. Coli alone or in combination with other pathogens were causative organism in majority of cases. So from the beginning of acute abdominal conditions a broad spectrum antibiotic like Cephalosporin and Amikacinbe initiated to prevent the infection in the operative wound.

\section{Conclusion}

Abdominal emergency due to non-traumatic pathology and traumatic injury is one of the most common emergency in casuality in different hospital. Despite the availability of so many sophisticated invasive and non invasive techniques of investigation in advanced modern hospital, surgeons are often in dilemma. The surgeons working in rural hospitals without the availability of modern investigation facilities face lot of problems in arriving at a decision, whether surgery is indicated or not. Patients requiring surgery, if not under- taken in proper time the condition may worsen with the consequent increase in morbidity and mortality. This had also same importance in avoiding unnecessary laparotomy.

It was learnt from the review of literature that diagnostic abdominal tapping, despite the number of articles advocating its acceptance and increasing experimental and clinical reports on its simplicity and safety its indication and limitations are yet to be clearly defined and at the same time the changing techniques and devices require standardization for routine use. From this study the following points were summarized.

a. A group of 100 patients with features of abdominal emergency (80 non-traumatic and 20 traumatic) were subjected to diagnostic peritoneal taping.

b. Clinical features and radiographs were not diagnostic in some cases. Moreover radiograph could not be taken in all cases due to poor general condition of the patient. Only in 72 cases radiograph were done. Routine investigations were not of much diagnostic value.

c. Overall results of abdominal tap was $78 \%$ positive with an incidence of $22 \%$ false negative tap.

i. Four quadrant and bilateral flank tap were equally reliable. Aspirating with 18-20 gauze needle was sufficient in getting aspirate fluid in $80 \%$ of cases and by washing the aspirated syring and examination for polymorph and RBC cells improved the diagnostic accuary by $10 \%$.

d. There were no complications encountered in the present series expect two. One died due to presence of concomitant pathology and one died due to grossly lacerated wound.

e. The gross appearance of the aspirate were diagnostic in most of the cases.

i. Presence of bile easily recognized by its colour and simple biochemical test.

ii. Faecal aspirate was diagnostic of colonic or ilealperforation

iii. Pus was diagnostic of gross infected pathology.

f. Bacterial culture and sensitivity studies of aspirate fluid were helpful in post operative management to control infection though they had little diagnostic importance.

g. Most of the aspirate in gastro intestional perforation gave positive culture of bacteria 
of which E.coli was the most common offended.

h. In comparison to the radiographical investigations, peritoneal tap was more valuable in the diagnosis of gastro-intestinal perorations. It was almost approximately $80 \%$ diagnostic in gastro- intestinal perforation.

i. Diagnostic abdominal tapping is strongly recommended for quick evaluation of acute abdominal emergency conditions, particularly in doubtful cases. If it is adopted meticulously by peripheral doctors, the mortality and morbidity of acute abdomen cases can be reduced to an appreciable extent.

j. As abdominal taping does not require any specialized equipments also not time consuming and with its inherent safety, it has special role in diagnostic adjuvant in abdominal emergency; especially in peripheral rural hospital on remote areas.

\section{References}

1. Thate RL, Jain CS, Nayak N, Dias AD. Diagnostic peritoneal tap of the acute abdomen. Indian J Surg. 1974;36:26-9.

2. Neuhof H, Cohen I. Abdominal puncture in the diagnosis of acute intra peritoneal diseases. Annals of Surgery. 1926;83:45462.

3. Giacobine JN, Siler VE. Evaluation of abdominal paracentesis. Surgery Gynec and Obst. 1960;110:676-86.

4. Moretz WH, Erickson WG. Peritoneal tap as an aid in the diagnosis of acute abdominal diseases. American Surgeon. 1954; 20:363-77.

5. Rao SPS, Parekh BR, Raina VK, Kapoor JP. Evalaution of Diagnostic abdominal paracentesis in acute surgical conditions of the abdomen. Indian Journal of Surgery. 1977;39:284-90

6. Trivedi DR, Shenoy CK, Waghmare AR, Bapat RD, Chaukar AP, Deshmukh SS et al. Diagnostic use of paracentesis periotoneal in the management of acute abdomen. Indian Journal of Surgery. 1971;33:395.

7. Khan M, Malik MS, Garyali RK, Dhar PM. Paracentesis peritoneii as a diagnostic aid in acute abdominal emergencies. Indian Journal of surgery. 1975;37:29-35.

8. Baker WNW, Mackie DB, Newcombe JF. Diagnostic paracentesis in acute abdomen. British Medical Journal. 1967;3:146-9.

9. Lamke LO, Varenhorst E. Abdominal paracentesis for early diagnosis of closed abdominal injury. Acta. Chir. Scand. 1978;144(1):21-5.

10. Sloop RD. The dominant role of paracentesis technics in the early diagnosis of blunt abdominal trauma. American Journal of Surgery. 1978;136(1):145-50.

11. Mc Partlin JF, McCarthy W. An appraisal of diagnostic paracentesis of the abdomen. British Journal of Surgery. 1971;58(7): 498-501.

12. Prout WC. An Evaluation of Diagnostic paracentesis in acute abdomen. British Journal of Surgery. 1968;55:853.

13. Singh J, Bharadwaj DN, Singh B. Paracentesis in the management of Acute Abdomen. Journal of Indian Medical Association. 1973;61(4):176-9.

14. Narasinga RT, Naik BB. Results of diagnostic peritoneal tap in acute abdomen. Indian Journal of Surgery. 1993;55(7):338-40.

15. Mahanta H, Das MK, Datta Choudhary SB. An experience with diagnostic paracentesis in 100 cases of acute abdomen. Journal of Indian Medical Association. 1990;88(5):125-9. 